\title{
External evaluation in Roald Dahl's The BFG
}

\author{
Joanna Deborah* \\ English Department, Faculty of Languages and Culture, Universitas Kristen Maranatha, \\ Bandung, Indonesia \\ ${ }^{*}$ Corresponding Author \\ Email: bjoz_911@yahoo.com
}

\begin{abstract}
There have been several significant changes in children's literature in the past few decades; one of them is the change in the narative style. Roald Dahl is one of the most prominent authors of children's literature that displays this particular change in his works. Dahl is known to utilize a creative narrative style in his works, and this is also seen in one of his children's novels discussed in this research: The BFG (1982). This research thus aims at analysing one part of the narrative structure called external evaluation which shows the function of narrator in the story as well as the effects of the use of such narrative style on children as the target readers. Using Labov's theory of narative structure and Genette's theory of narratology, the results of the analysis shows that Dahl utilizes the function of narrator in the external evaluations to help children as his target readers to get a better understanding of the story as well as to build a close connection with them, resulting in the more enjoyable reading experience for the children.
\end{abstract}

Keywords: Children's literature; narratology; narrative structure; external evaluation; narrator

Received: $\quad$ Revised:

20 November 20198 January 2020
Accepted:

10 January 2020
Published:

29 February 2020

\section{INTRODUCTION}

Over the past decades, children's literature has undergone significant changes in terms of its content, writing, and media. Previously, children's literature mostly concerns with themes of good versus evil or moral lessons, is written in a conventional narrative style, and is usually presented in the conventional form of printed books. In contrast, children's literature in modern days goes past the conventional themes and explores various new issues, is written in a more creative narrative style, and is presented in various new media, such as e-books or graphic books, and even adapted into movies, games, and stage musicals.

Roald Dahl is one of the most prominent authors of contemporary children's literature that depicts these significant changes in his works. Dahl is a prolific British author who has produced many children's books, adults' novels, short stories, poems, and even movie scripts. He is included in The Times' list of 50 greatest British writers since 1945 ("The 50 Greatest British 
Deborah, J. (2020). External Evaluation in Roald Dahl's the BFG. EduLite: Journal of English Education, Literature, and Culture, 5 (1), 126-135. DOI: http://dx.doi.org/10.30659/e.5.1. 126-135

Writers," 2008) and regarded as "one of the greatest storytellers for children of the $20^{\text {th }}$ century" ("Once Upon A Time," 2010). In terms of writing style, Dahl is especially known to make use of innovative language play and creative narrative style in conveying his stories to the readers. One of his works that shows the use of this creative narrative style is The BFG.

The BFG (1982) is one of Dahl's best and most popular children's novels other than Matilda and Charlie and the Chocolate Factory (Pai, Framke, Romano, \& Grady, 2016). The novel tells about the encounter between Sophie, a little orphaned girl, and the BFG - a big, friendly giant. Together with the BFG, Sophie succeeds in preventing the other cruel giants from eating human beings. The novel itself contains many examples of innovative language play and utilizes a creative narrative style, which displays the aforementioned changes in the children's literature.

The popularity of Dahl as an author undeniably results in the huge amount of researches conducted on his works, including The BFG. Nevertheless, most of those researches discuss The BFG in terms of issues it raises. A research by Kyriaki Angelidou (2013), for example, discusses whether the content of the novel is really suitable for children despite the fact that it is considered a piece of children's literature. A more recent research by A. Robin Hoffman (2010) investigates the children's response towards the novel based on reviews posted in a particular website. Another research by Jennifer Trieu (2017) explores the notion of consumption through the representation of food and power in the novel while the research by Suyanti Fatma Umayfa (2018) raises the issue of self-identification. There are indeed some researches that discuss the writing of the novel, such as the ones conducted by Heli Koskinen (1998) and Dominic Cheetam (2016), but the focus is usually on the language play. There has not been any research specifically discussing the narrative structure, even though it is obviously one element that causes Dahl's writing to be so enjoyable for the readers. Thus, based on the gap in the previous studies, this particular research attempts to offer an analysis focusing on one element of the narrative structure - the external evaluation - that supports Dahl's creativity in writing.

As this research aims at analysing the external evaluation in The BFG, there are two theories that will be used as the framework. The first is William Labov's theory of narrative structure. In his theory of narrative structure, Labov suggests that a narrative usually consists of six elements: abstract, orientation, complicating action, evaluation, resolution, and coda (Toolan, 1998). Abstract refers to the one-sentence summary usually put at the beginning of a narrative which tells the readers of what is/are going to take place. Orientation is a part of a narrative which introduces the characters involved in the story, the setting of time, and the setting of place. Complicating action contains the main events in the narrative. Evaluation refers to the details added to the basic story which in turn can make the plain complicating action become more interesting. Resolution is the ending of a narrative. Coda refers to a part of a narrative which provides a connection between the story and the readers. Coda usually "supplies a moral or lesson learned by the protagonist or teller" (Toolan, 1998, p. 138) and thus enables the readers to relate with the story. 
Toolan (1998), in his discussion on Labov's theory, states that the six elements of narrative structure mentioned above are not equal to one another. Some are required while the others are optional. For example, complicating action and resolution are usually needed to form a narrative while abstract and coda may or may not be necessary depending on many factors like the author's purpose or the target readers. However, Toolan argues that what seems to be optional is actually the most important, and he states such an argument when specifically discussing the evaluation in contrast with the complicating action:

In other words, we attend to narratives for their evaluation, not their complicating action - despite the fact that the latter is always required and the former is seemingly optional. There is an analogy with a similar paradox in relation to sentence structure, where adjectival and, especially, adverbial material is often the more valuable information relayed, being the more specific information, while the content of the main verb may be relatively banal and predictable - and yet a main verb is structurally required, while ' $A$ ' material (adverbial or adjectival) is structurally optional (Toolan, 1998, p. 139).

The evaluation itself, as an optional but very important element of narrative structure, is divided into two types: internal and external. As the name suggests, internal evaluation refers to details added within complicating action sentences while external evaluation refers to details added outside complicating action sentences (Toolan, 1998, p. 139). These additional details, especially the ones in the external evaluation, usually appear in the form of the narrator's commentaries on the events happening in the narrative.

The narrator's role in a narrative is further discussed by Gerard Genette in his theory of narratology, which will be used as the second theory to support the analysis in this research. In a work entitled Narrative Discourse: An Essay in Method (1980), Genette divides the analysis of the elements of narrative into four categories: narrative mood, narrative instance, narrative level, and narrative time. However, as this research will specifically highlight the narrator's role in the external evaluation, the explanation of the theory will focus only on the function of narrator in the narrative mood category.

According to Genette (1980), narrative mood concerns with the distance and the function of narrator in a narrative. The distance of narrator can be determined through the types of speech the narrator uses in telling the story while the function of narrator - which is eventually related to his distance or, instead, involvement with the story and the readers - is divided into narrative, directing, communication, testimonial, and ideological function.

The narrative function is performed simply when the narrator narrates his story. This is the most common function of a narrator considering that every story will be narrated by a narrator; there will be no narrative without the existence of a narrator. The directing function is performed when the narrator "interrupts the story to comment on the organization or articulation of his text" (Guillemette \& Levesque, 2016) while the communication function is performed when the narrator "addresses the narratee directly . . . in order to establish or maintain contact with him or her" (Guillemette \& Levesque, 2016). The testimonial function is performed when the narrator "affirms the truth of his story, the degree of precision in his narration, his certainty regarding the events, his sources of information, and the like" (Guillemette \& Levesque, 
Deborah, J. (2020). External Evaluation in Roald Dahl's the BFG. EduLite: Journal of English Education, Literature, and Culture, 5 (1), 126-135. DOI: http://dx.doi.org/10.30659/e.5.1. 126-135

2016), and the ideological function is performed when the narrator "interrupts his story to introduce instructive comments or general wisdom concerning his narrative" (Guillemette \& Levesque, 2016). Utilizing these two theories, this research will analyse the function of narrator in the external evaluation found in The BFG.

\section{METHOD}

This research is categorized as a descriptive qualitative research. Descriptive research is a type of research that "aims to accurately and systematically describe a population, situation, or phenomenon" (McCombes, 2019), while according to Punch, qualitative research is a type of research "where the data are not in the form of numbers" (as cited in McLeod, 2019). The researcher conducted the study by reading Roald Dahl's The BFG as the research object and dissecting the text using Labov's theory of narrative structure in order to separate the part of the text that can be categorized as external evaluation from the others. The researcher then analysed the function of the narrator in the aforementioned external evaluation using Genette's theory of narratology and draws some conclusions based on the analysis.

\section{RESULTS AND DISCUSSION}

The dissection of the text using Labov's theory of narrative structure results in the finding of 17 data of external evaluations. However, the analysis presented in this section will only discuss some representative data that can clearly show each function of the narrator. The analysis will also exclude the discussion on the narrative function of narrator as it is deemed unnecessary. As has been stated previously, every narrator will automatically perform the narrative function when he narrates his story. This means that all external evaluations found in the text will also show the narrative function of the narrator. Thus, the analysis in this section will focus more on discussing the external evaluations which display the other four functions of the narrator.

\section{Directing function of the narrator}

The most dominant function of narrator found in the external evaluations is the directing function, which is 6 out of 17 data (please note that some data may show more than one function of narrator). This function is performed when the narrator "interrupts the story to comment on the organization or articulation of his text" (Guillemette \& Levesque, 2016), which is similar to some extent to the stage directions found in plays. This function thus helps the readers to get a better understanding of what is happening in the story. As the narrator tries to help the readers with his directions, this function also suggests the narrator's involvement with the story and the readers. This function can be seen in the following example:

Sophie started to read the labels. The first one seemed long enough to her. It went right round the jar, and as she read it, she had to keep turning the jar. This is what it said: HARD AT MY TEECHER IN A SPHESHAL WAY, I IS ABLE TO PUT HER TO 
SLEEP, SO I KEEP STARING AT HER AND IN THE END HER HEAD DROPS ON TO HER DESK AND SHE GOES FAST TO SLEEP AND SNORKLES LOUDLY. THEN IN MARCHES THE HEAD TEECHER AND HE SHOUTS 'WAKE UP MISS PLUMRIDGE! HOW DARE YOU GO TO SLEEP IN CLASS! GO FETCH YOUR HAT AND COTE AND LEAVE THIS SCHOOL FOR EVER! YOU IS SACKED! BUT IN A JIFFY I IS PUTTING THE HEAD TEECHER TO SLEEP AS WELL, AND HE JUST CRUMPLES SLOWLY TO THE FLOOR LIKE A LUMP OF JELLY AND THERE HE LIES ALL IN A HEAP AND STARTS SNORKELLING EVEN LOWDER THAN MISS PLUMRIDGE. AND THEN I IS HEARING MY MUMMY'S VOICE SAYING WAKE UP YOUR BREAKFUST IS REDDY.

'What a funny dream,' Sophie said. (Dahl, 1999, pp. 87-88)

This scene is a part of a long conversation between Sophie and the giant about the latter's occupation as a dream catcher. The giant tells Sophie that he always writes down the content of each dream he has caught on a label and attaches that label on the jar in which he keeps the dream.

It can be seen in the excerpt above that the external evaluation (the words put in bold in the excerpt) is placed between two parts of a scene which have different narrative levels. The part when Sophie is reading the label happens in the intradiegetic level - which is the world of the story - while the content of the dream written in all capital letters on the label by the giant happens in the metadiegetic level - which is also known as the story within a story. This means that the external evaluation serves as a bridge between the two different narrative levels, which eventually helps the readers to understand the flow of the story. Without this external evaluation, the readers - especially children readers - might be confused about the connection between the former and the latter part of the scene as the two discuss totally different characters and describe different things. The external evaluation in this particular example thus provides a logical connection that helps the readers understand the relation between the former and the latter part of the scene - that the latter part is actually the story within a story that Sophie reads on the label. As the external evaluation provides the readers with directions on the flow of the story, it can be concluded that the aforementioned external evaluation shows the directing function of the narrator and suggests his involvement with the readers and the story he tells.

\section{Communication function of the narrator}

The second most dominant function of narrator found in the external evaluations is the communication function, which is 5 out of 17 data. This function is performed when the narrator addresses the readers directly "in order to establish or maintain contact with [them]" (Guillemette \& Levesque, 2016). As the narrator makes an effort to greet the readers directly, this function suggests the narrator's involvement with the story and the readers. Below is one example of the communication function of narrator in the text:

Under the blanket, Sophie waited.

After a minute or so, she lifted a corner of the blanket and peeped out. For the second time that night her blood froze to ice and she wanted to scream, but no sound came out. There at the window, with the curtains pushed aside, was the enormous long pale wrinkly face of the Giant Person, staring in. The flasing black eyes were fixed on Sophie's bed.

The next moment, a huge hand with pale fingers came snaking in through the window. This was followed by an arm, an arm as thick as a tree-trunk, and 
Deborah, J. (2020). External Evaluation in Roald Dahl's the BFG. EduLite: Journal of English Education, Literature, and Culture, 5 (1), 126-135. DOI: http://dx.doi.org/10.30659/e.5.1. 126-135

the arm, the hand, the fingers were reaching out across the room towards Sophie's bed.

This time Sophie really did scream, but only for a second because very quickly the huge hand clamped down over her blanket and the scream was smothered by the bedclothes.

Sophie, crouching underneat the blanket, felt strong fingers grasping hold of her, and then she was lifted up from her bed, blanket and all, and whisked out of the window.

If you can think of anything more terrifying than that happening to you in the middle of the night, then let's hear about it. (Dahl, 1999, pp. 8-9)

The excerpt above contains the description of the first meeting between Sophie and the giant. Sophie, who cannot fall asleep one particular night, accidentally sees the giant through the window of her bedroom in the orphanage. The giant, aware of Sophie's watching him, decides to snatch Sophie out of her bed to prevent her from telling other people about his existence. This scene is then followed by the narrator's external evaluation as well as the next scene explaining Sophie's thought about that happening.

In this external evaluation, it can be seen that the narrator addresses the readers directly using the term "you", which signifies his attempt to interact with the readers while telling his story. The narrator also asks the readers to think whether they can find any other experience which is more terrifying than the one happening to Sophie. This shows that the narrator does not only tell his story but also encourages the readers to participate actively in the story he tells. Through the use of this external evaluation, the narrator can thus make the readers - especially children readers - feel involved in the story, resulting in the readers' enjoying the story more as it becomes relatable. In general, as the narrator try to communicate with the readers in his own way, it can be concluded that this external evaluation shows the communication function of the narrator and suggests the narrator's involvement with the story and the readers.

\section{Testimonial function of the narrator}

The next function of narrator found in the external evaluations is the testimonial function, which is 2 out of 17 data. This function is performed when the narrator, whether directly or indirectly, ensures the readers that what he says in the story is true, and that the source of the information he has is credible. This function is also performed when the narrator expresses his feelings about the story, signaling his emotional connection with the story he tells (Guillemette \& Levesque, 2016). Thus, this function suggests the narrator's involvement with the story and the readers. Below is one example of the testimonial function found in the text:

Sophie read some of them, she said, 'These are very good. I think perhaps one day you could become a real writer.'

'Oh, I would love that!' cried the BFG. 'Do you think I could?'

'I know you could,' Sophie said. 'Why don't you start by writing a book about you and me?'

'Very well,' the BFG said. 'I'll give it a try.'

So he did. He worked hard on it and in the end he completed it. Rather shyly, he showed it to the Queen. The Queen read it aloud to her grandchildren. 
Then the Queen said, 'I think we ought to get this book printed properly and published so that other children can read it.' This was arranged, but because the BFG was a very modestgiant he wouldn't put his own name on it. He used somebody else's name instead.

\section{But where, you might ask, is this book that the BFG wrote?}

It's right here. You've just finished reading it. (Dahl, 1999, pp. 177178)

This scene happens at the end of the story. Sophie is telling the giant to be a writer as she thinks the giant's language has improved a lot and she believes that the giant can write good stories. The giant thus really writes down his adventure with Sophie and gets his story published in the form of a book.

In this external evaluation, the narrator voices what might be the readers' question regarding the existence of the book and informs the readers that the book is actually the one that they have just finished reading. By informing the readers about the existence of the book, the narrator seemingly ensures his readers that the story he tells is really true. If the book the giant has written does exist - that is the one in the readers' hands - it is highly possible that the story told in the book is also true. By providing the readers with the evidence that can attest the truth of his story, the narrator thus has indirectly performed his testimonial function in this external evaluation. Furthermore, by stating that the book does exist, the narrator, at the same time, is also able to leave the readers with a lingering feeling that the experience, the adventure they have just finished reading is real, which eventually causes the readers - especially children readers - to enjoy the story more.

\section{Ideological function of the narrator}

The least dominant function of narrator found in the external evaluations is the ideological function, which is 1 out of 17 data. This function is performed when the narrator, whether explicitly or implicitly, states his point of view regarding certain matters in the story (Guillemette \& Levesque, 2016). The matters that he discusses do not have to be something important; they can be something really trivial. The essence is that the narrator expresses his standing position regarding those matters - whether he agrees or disagrees with them. As the narrator expresses his point of view about the matters he discusses in the story, it can be said that this particular function suggests the narrator's involvement with the story and the readers. Below is the example of external evaluation containing the ideological function of narrator in the text:

With a swish, the great curtains were pulled aside.

The maid screamed.

Sophie froze to the window-ledge.

The Queen, sitting up in her bed with The Times on her lap, glanced up sharply. Now it was her turn to freeze. She didn't scream as the maid had done. Queens are too self-controlled for that. She simply sat there staring wide-eyed and white-faced at the small girl who was perched on her window-sill in a nightie. (Dahl, 1999, p. 134) 
Deborah, J. (2020). External Evaluation in Roald Dahl's the BFG. EduLite: Journal of English Education, Literature, and Culture, 5 (1), 126-135. DOI: http://dx.doi.org/10.30659/e.5.1. 126-135

The excerpt above is the description of the first meeting between Sophie and the Queen of England. Sophie wants to ask the Queen to help her prevent the cruel giants from eating human beings in England. Therefore, with the help of the friendly giant, Sophie climbs up to the Queen's bedroom on the second floor from outside the palace and sits on the Queen's window-sill, waiting for the Queen to wake up in the morning. The excerpt then shows the reaction of each character involved in the scene - Sophie, the Queen's maid, and the Queen herself - when they finally see one another.

In this external evaluation, it can be seen that the narrator implicitly compares the maid's reaction to the Queen's when they see Sophie. The narrator describes that the maid scream, which is actually a perfectly normal reaction shown by a person given the circumstances. After all, it is not every day that a person finds a total stranger sitting on the window-sill of his/her bedroom. However, the narrator then states that the Queen does not scream in contrast to the maid's reaction - and proceeds on commenting that such a thing can happen because queens, in general, are usually too self-controlled. By using the rather cynical words "too self-controlled" to portray the Queen's reaction, the narrator implicitly states that he agrees more with the maid's normal reaction and - at the same time - implies that the Queen is too strict and stiff. In general, as the narrator shows his standing position regarding a certain detail in the story, it can be concluded that the narrator has performed his ideological function in this external evaluation.

\section{CONCLUSION}

As has been stated previously, the dissection of The BFG results in the findings of 17 data of external evaluations. In these external evaluations, the directing function becomes the most dominant function of narrator. This can be interpreted that the narrator concerns first and foremost with the readers' understanding of the story. Considering that the primary target readers of this novel are children who are very likely to have less ability than adults in perceiving the flow of the story, it is important for the narrator to ensure that they understand the story first before being able to enjoy it. Thus, the narrator provides the readers with sufficient directions to understand the story.

Other than the directing function, the communication function of narrator is also quite dominant in the external evaluations. This shows how the narrator wants to build a close connection with the story and the readers. By addressing the readers directly, the narrator is able to make the readers feel that they are involved in the story - not just being passive observers or listeners - and thus enables them to enjoy the story more.

The next function of narrator found in the external evaluations is the testimonial function. This function actually strengthens the effect of closeness that has been built by the communication function. By providing the readers with proofs, the narrator can reduce the distance between the story and the readers; the narrator can convince the readers that the story he tells is true. This results in the reader's feeling that the events they experience in the story are real, which eventually can add to their enjoyment in reading the story. 
The least dominant function of narrator found in the external evaluations is the ideological function. This function happens when the narrator shows his standing position about a certain matter in the story. However, as this function is the least dominant, it can be interpreted that narrator does not think it necessary to show his stance to the readers. This happens most probably because the narrator considers his primary target readers too young to really understand deeper issues he might convey in his writing. Thus, the narrator chooses to focus more on entertaining the children readers with the story he tells instead of demanding them to think further about deeper issues.

In general, based on the analysis of findings, it can be concluded that Dahl as the author has been able to convey his story effectively to readers by using all the functions of narrator in the external evaluations. In short, he has succeeded in constructing relatable and enjoyable stories for children through his use of creative narrative style.

\section{REFERENCES}

Angelidou, K. (2013). The invention of children's literature: The case of the mischievous Roald Dahl (Master's thesis). Retrieved March 6, 2019, from http://ikee.lib.auth.gr/record/135332/files/GRI-2014-13318.pdf

Cheetam, D. (2016). Dahl's neologisms. Children's Literature in Education, 47(2), 93-109. Retrieved July 25, 2019, from https://link.springer.com/article/10.1007/s10583-015-9254-2

Dahl, R. (1999). The BFG. London, UK: Puffin Books.

Genette, G. (1980). Narrative discourse: An essay in method. (J. E. Lewin, Trans.). Ithaca, NY: Cornell University Press.

Guillemette, L., \& Levesque, C. (2016). Narratology. In Signo: Theoretical semiotics on the web. Retrieved January 22, 2019, from http://www.signosemio.com/genette/narratology.asp

Hoffman, A. R. (2010). The BFG and the Spaghetti Book Club: A case study of children as critics. Children's Literature in Education, 41(3), 234-250. Retrieved July 25, 2019, from https://link.springer.com/article/10.1007/s10583-010-9106-Z

Koskinen, H. (1998). "Words is oh such a twitch-tickling problem": Anomalous features in Roald Dahl's The BFG and its Finnish translation (Master's thesis). Retrieved March 6, 2019, from https://ivx.jyu.fi/bitstream/handle/123456789/7411/1514.pdf?...1

McCombes, S. (2019). Descriptive research. Retrieved November 6, 2019, from https://www.scribbr.com/methodology/descriptive-research/

McLeod, S. (2019). What's the difference between qualitative and quantitative research? Retrieved November 6, 2019, from https://www.simplypsychology.org/qualitative-quantitative.html

Once upon a time, there was a man who liked to make up stories. (2010, December 12). Retrieved November 6, 2019, from 
Deborah, J. (2020). External Evaluation in Roald Dahl's the BFG. EduLite: Journal of English Education, Literature, and Culture, 5 (1), 126-135. DOI: http://dx.doi.org/10.30659/e.5.1. 126-135

https://www.independent.co.uk/voices/commentators/once-upon-atime-there-was-a-man-who-liked-to-make-up-stories-2158052.html

Pai, T., Framke, C., Romano, A., \& Grady, C. (2016, September 13). Roald Dahl's 11 best - and worst children's books, ranked. Retrieved November 6, 2019, from https://www.vox.com/2016/7/1/12008402/roald-dahlbooks-best-ranked

The 50 greatest British writers since 1945. (2008, January 5). Retrieved November 6, 2019, from https://www.thetimes.co.uk/article/the-50greatest-british-writers-since-1945-ws3g69xrf90

Toolan, M. (1998). Language in literature: An introduction to stylistics. London, UK: Arnold.

Trieu, J. (2017). Food and power in Roald Dahl's children's fiction (Doctoral dissertation). Retrieved March 6, 2019, from http:/ / www.tara.tcd.ie/handle/2262/81722

Umayfa, S. F. (2018). Self-identification of human and giant as portrayed in The BFG novel: A study of psychoanalysis (Bachelor's thesis). Retrieved March 6, 2019, from http://digilib.uin-suka.ac.id/29836/2/14150040_BABI_IV-atau-V_DAFTAR-PUSTAKA.pdf 